\title{
AUGUST RUHS
}

Leneide Duarte-Plon, de Viena

"Lacan renovou a psicanálise, que hoje

está ameaçada pelas neurociências."

V

iena viu nascer a psicanálise numa época de efervescência cultural extraordinária, o final do século XIX. Hoje, um dos mais famosos museus da cidade fica no número 19 , da rua Berggasse, na casa onde Freud morou e trabalhou até deixar a cidade, em 1938, para se refugiar do nazismo, em Londres.

Talvez se possa dizer que as histéricas austríacas eram mais suscetíveis à descoberta de Freud do que as histéricas francesas da Salpêtrière. Mas todas foram importantes, pois foi uma paciente que levou Freud a interromper o tratamento com hipnose e lhe disse "Deixe-me tranqüila, não me toque, escuteme", comenta August Ruhs sobre o caldo de cultura científica e literária que favoreceu a descoberta da psicanál ise por Freud.

Mas a psicanálise não teria hoje a importância que adquiriu se o psicanalista francês Jacques Lacan não tivesse feito uma conferência em Viena, em 1955, defendendo um "retorno a Freud", revigorando o movimento psicanalítico. Para marcar os 50 anos dessa conferência, o psiquiatra e psicanalista austríaco August Ruhs, diretor-adjunto da Clínica Universitária de Psicanálise e de Psicoterapia de Viena, organizou na capital austríaca um colóquio com alguns dos mais respeitados psicanalistas austríacos e com os psicanalistas franceses Elisabeth Roudinesco e Michel Plon, autores do Dicionário da Psicanálise.

Segundo Ruhs, sem a conferência de Lacan na cidade, há 50 anos, a psicanálise estaria hoje limitada ao papel que ela tem nos países anglo-saxões, ou seja, é bem menos importante que na França, no Brasil e na Argentina, onde ela mais profundamente se implantou: “Um dos enormes impactos de Lacan sobre a psicanálise foi o de alargar seu campo de relações com a filosofia e com outras ciências humanas. Se existe hoje tal 
produção de publicações nessas disciplinas é, sobretudo, graças a Lacan eà renovação teórica que ele possibilitou", diz o psicanalista.

Em 2006, o mundo inteiro comemora os 150 anos do nascimento do Pai da Psicanálise e vários encontros e publicações vão acontecer em Viena.

LENEIDE DUARTE-PLON - 0 berço da psicanálise poderia ter sido outra cidade? AUGUST RUHS - É uma pergunta que se faz sempre. Em geral, essa questão é centrada nos personagens da descoberta, isto é, Freud e seu colega Breuer, que teve um papel importante na descoberta porque foi com ele que se deu a passagem da hipnose catártica à hipnose investigativa. Ou então Charcot, que teve grande influência sobre Freud. Então tudo fica centralizado nos homens, mas a gente esquece a quem se deve de fato a psicanálise: aos pacientes. Talvez se possa dizer que as histéricas austríacas eram mais suscetíveis à descoberta de Freud do que as histéricas francesas da Salpêtrière. Mas todas foram importantes, pois foi uma paciente que levou Freud a interromper o tratamento com hipnose e Ihe disse: "Deixe-me tranqüila, não me toque, escute-me". E foi essa escuta que levou Freud a descobrir os desejos inconscientes camuflados pelo grande espetáculo da histérica. E talvez a cidade deViena fosse propícia, porque Freud nutria essa lenda de um landsome hero (herói solitário), um Titã incompreendido por todos... o que não é verdade, pois em torno dele havia uma cultura que ia na mesma direção que ele, não em medicina, é certo, mas em literatura e nas artes. Ainda mais Schnitzler, que Freud reconhecia como sendo seu alter ego, uma espécie de sósia, de quem ele dizia: "Ele vai pelo mesmo caminho". Então, era uma cultura que favorecia e não apenas a um ou dois homens. Eram os homens que estavam lá naquele momento e também as pessoas doentes.

LDP - Qual éa importância para a história da psicanálise do si mpósio sobre os 50 anos da conferência de Lacan, em Viena, pregando um 'retorno a Freud'?

AR - Para a história da psicanálise, essa comemoração da conferência de Lacan centrada num retorno a Freud já faz parte das grandes festividades de 2006, quando se festejam os 150 anos de Freud. Este simpósio significou "não esqueçamos de Freud", mas também não esqueçamos que a psicanálise é como um trabal ho sempre inacabado, o que supõe uma volta às origens para beber na fonte e para que as inovações possam ser mantidas no eixo da descoberta freudiana. A psicanálise tem e terá sempre desafios a enfrentar, ela deve estar sempre em evolução a fim de poder responder às mudanças que acontecem na sociedade. Por isso, ela não pode perder seus princípios, isto é, deve continuar a buscar os motivos secretos e internos de cada manifestação do psiquismo humano e ao mesmo tempo não deve se perder no passado para não ser superada pelos acontecimentos. 
LDP - Se Lacan não tivesse proposto esse retorno a Freud, qual teria sido o destino da psicanálise? AR - Ela não estaria ameaçada, mas teria evoluído para o que se tornou o modelo anglo-americano: seria mais medicalizada e teria perdido muito de sua característica de ser aberta a outras disciplinas. Teria ficado restrita à função terapêutica porque um dos enormes impactos de Lacan sobre a psicanálise foi o de alargar seu campo de relações com a filosofia e com outras ciências humanas. Se existe tal produção de publicações nessas disci plinas é sobretudo graças a Lacan e à renovação teórica que ele possibilitou com sua concepção tópica em termos de imaginário, simbólico e real, critérios queFreud não desenvolverae, sendo assim, a expressão do inconsciente pôde ser enriquecida por conceitos lacanianos.

LDP - A cidade de Freud,Viena, etá preparando uma programação para festejar este ano os 150 anos do Pai da Psicanálise?

AR - Estão sendo preparados espetáculos, publicações e projetos a cargo de instituições psicanalíticas. Por exemplo, haverá um grandeciclo de Conferências Sigmund Freud. Será a primeira vez que isso acontece na cidade, e contará com a colaboração entre a SociedadeVienense de Psicanálise e o Círculo deTrabal ho Psicanalítico deViena, as duas grandes sociedades vienenses, que estão mais próximas agora; e do Museu Sigmund Freud e da Sociedade Sigmund Freud, que se ocupam mais da história e da tradição e que estão mais ligados à pessoa de Freud que à sua obra teórica. Haverá também colaborações com outras disciplinas: por exemplo, as neurociências querem fazer com os analistas um congresso no mês dejulho, tendo como tema 'A procura do amor perdido', que vai se orientar sobre a questão 'A psicanálise do amor e do ódio' e'A biologia da atração'. A psicanálise corre sempre o risco de ser anexada por uma outra disciplina, como as neurociências, e é por isso que um retorno a Freud nesse sentido lacaniano é um contrapeso para fazer frente a essa ameaça, isto é, para evitar que a psicanálise se perca na modernidade das ciências neurológicas, neurofisiológicas, neuroanatômicas.

LDP - Que tipo de registro chegou até nós dessa conferência de Lacan em Vienna, em 1955?

AR - Nenhum vestígio dessa conferência chegou até nós. Apenas duas ou três pessoas que ainda estão vivas ouviram Lacan em Viena. U ma pessoa se lembra que teve de traduzir o texto, mas desistiu depois de algumas frases. Uma outra diz que era um pouco tedioso, ninguém compreendeu nada. E a terceira pessoa idosa que se lembra, o senhor Arnold, citado por Lacan entre as pessoas que ele encontrou, não se lembrava de nada quando o entrevistei.

LDP - Lacan fez essa conferência em francês?

AR - Segundo uma pessoa presente, ele fez a conferência em francês e parece que o texto integral foi distribuído aos presentes. Mas os vestígios desse texto foram 
destruídos quando puseram abaixo a casa onde funcionava a clínica de psiquia tria para construir um novo prédio do hospital geral. Os arquivistas me disseram que muitos textos também foram jogados no lixo. Alguém salvou uns papéis mas o discurso de Lacan desapareceu.

LDP - Como o senhor vêa psicanálise na Áustria, hoje? Quantos psicanalistas existem e como des se situam na sociedade vienense?

AR - Aqui existe a tendência a se dizer "Freud, sim, mas a psicanálise, não". Como se Freud fosse um grande homem, interessante, fumante de charutos, um grande colecionador de estatuetas, mas sua obra fosse considerada hoje pela maioria das pessoas como uma disciplina um pouco esdrúxula, que não é verdadeiramente uma ciência. Há muitos preconceitos. E principalmente, nos dias atuais, há um movimento, inclusive na Áustria, na direção de uma'biologização' da vida, uma espécie de atemporalidade, no sentido de desprezar as condições do meio ambiente na formação do sujeito e de propagar as idéias vindas da genética. Por isso, há um enfraquecimento da psicanálise. E também, e isso é puramente austríaco, a lei das psicoterapias institucionais de 1991 levou ao reconhecimento de cerca de 15 escolas de psicoterapia. Isto significa que, aqui, a psicoterapia reconhecida pelo Estado se divide entre 15 e 18 escolas equivalentes, das quais a psicanálise é uma delas. Esqueceram que ela era a disciplina originária ou uma das duas ou três disciplinas pioneiras. Os princípios para a formação dos psicoterapeutas vêm da psicanálise, mas, ao mesmo tempo, comeram os cadáveres para fazer a psicanálise desaparecer, como se a psicoterapia fosse a mesma coisa que a psicanálise.

LDP - Quantos psicanalistas exercem a psicanálise na Áustria?

AR - Existem entre 500 a 700 psicanalistas.

LDP - Como os psicanalistas austríacos reagi ram aos ataques à psicanálise feitos no Livro negro da psicanálise?

AR - Eles não conhecem o livro. Aqui, ele ainda não foi publicado.

LDP - 0 senhor acha que ele será traduzido para 0 alemão?

AR - Acho que não, pois o que vem da França se espalha em círculos específicos, e estes são contra o livro. As pessoas que estariam de acordo com ele não o leram. Os livros de psiquiatria que vêm da França não são muito divulgados. Por exemplo, o livro de Sokal sobre a impostura não teve grande repercussão aqui na Áustria. 